\title{
Self assessment exercises in tropical remote medicine
}

\author{
JE Smith, S Leigh-Smith
}

Surg Lt Cdr J E Smith MBBS MRCP RN Specialist Registrar in Accident and Emergency Medicine Defence Medical Services

jason.smith20@virgin.net

Surg Lt Cdr

$S$ Leigh-Smith

MB ChB MRCGP

FRCS Ed(A\&E) RN

Specialist Registrar in

Accident and

Emergency Medicine

Defence Medical

Services

Royal Infirmary of Edinburgh, Edinburgh, EH3 9YW
You are the Medical Officer to a unit undergoing jungle training in Belize. The following questions relate to patients that may present to you during your deployment.

1. A 22-year-old corporal presents to you with a wound on his left lower leg. He tells you that it started a week previously as a small blister following a bite, but after he scratched it the wound broke down and spread. He says that it is painful. On examination there is a $2 \mathrm{~cm}$ by $2 \mathrm{~cm}$ area of ulceration over the lower third of the left shin. The edges are raised and erythematous, and there is slough at the base of the ulcer.

a. What is the likely diagnosis?

b. How would you treat the condition?

c. Are you going to keep him out under field conditions?

2. A 40-year-old sergeant is bitten on his right buttock by a snake whilst undertaking his ablutions behind a tree. He did not get a clear view of the markings of the snake, but tells you that it was a big one. Other members of the party are keen to administer first aid, with suggestions ranging from urinating on it, sucking out the poison, or cutting it open to let it bleed. Apart from localised pain around the site of the bite, he is complaining of no other symptoms.

a. What first aid measures are appropriate? b. What poisonous snakes may have caused the bite?

and ten small insects which you identify as ticks.

a. What is the best method to remove ticks? b. What diseases are transmitted by ticks?

c. What symptoms should the soldiers look out for after a tick bite?

5. Your Commanding Officer presents to you with a large boil on his head. Examination reveals a 3 by $3 \mathrm{~cm}$ abscess on the scalp with a small central hole and a white spiracle moving in and out of it.

\section{a. What is the diagnosis?}

b. How should this condition be treated?

c. What is the most important measure to prevent the condition occurring?

6. Six months after returning from jungle training a trooper complains of an ulcer on his face that he has been ignoring for some weeks. Examination reveals a $1 \mathrm{~cm}$ diameter ulcer with erythematous raised borders and infected slough in the base. $\mathrm{He}$ is systemically well. You start him on antibiotics and review him a week later with an atlas of tropical dermatology by your side. As the ulcer has not changed you suspect a diagnosis of cutaneous leishmaniasis.

a. What are the keys to the diagnosis?

b. What is your management plan?

c. What insect vector is responsible for this infection?

d. What steps can be taken to prevent infection? management?

3. One of your soldiers gives a two day history of feeling feverish and waking up soaked in sweat. He complains of no other symptoms, but says he generally feels rotten. Examination reveals he is alert and orientated, haemodynamically normal, with no neurological deficit. $\mathrm{He}$ has several insect bites around his belt line and over his hands and wrists.
a. What is your differential diagnosis?
b. What is your management plan?

4. On their first day at the jungle training school several soldiers complain that after washing in the stream they have noticed that they are playing host to between one

\section{Answers to self assessment exercises}

\section{Question 1}

a. A tropical ulcer.

b. Clean the ulcer and dress with a moist non-adherent dressing. Start parenteral (if possible, or oral if not) penicillin.

c. This depends on the circumstances and the degree of compromise to function although the ulcer is unlikely to heal under field conditions.

\section{Discussion}

Tropical ulcers usually result from minor 


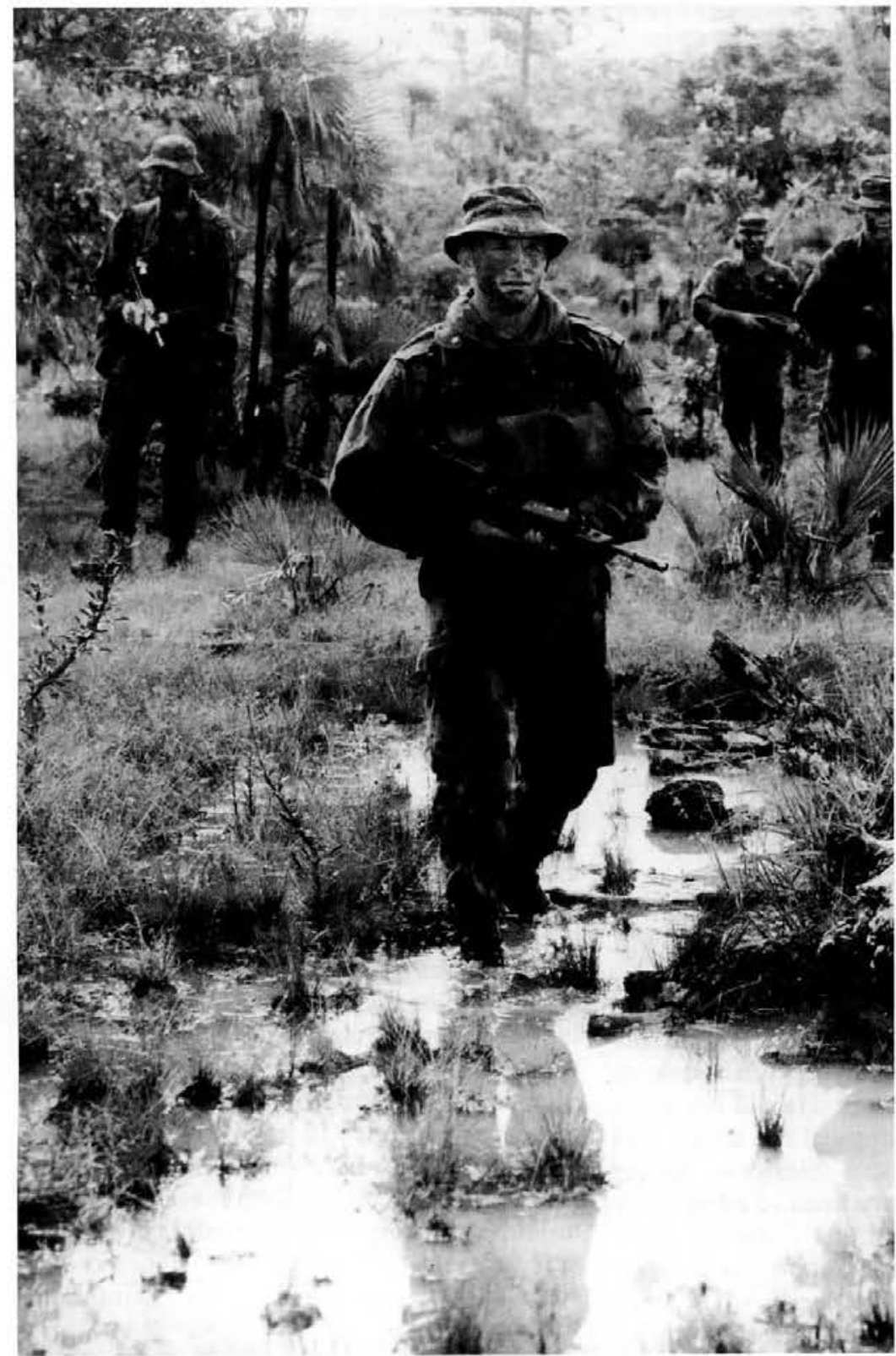

trauma to the lower limbs, such as a bite or scratch, and start as a small papule or blister that breaks down to form an ulcer. This spreads rapidly causing a painful lesion with raised red margins, which may expose underlying tissues. There is usually mixed growth of organisms on culture $(1,2)$. If left untreated, the progress usually slows, and the lesion becomes less painful. Chronic ulcers may last for many years, and are occasionally associated with malignant change to squamous cell carcinoma (1).

Tropical ulcers usually respond well to a course of penicillin if treatment is started early. The wound should be dressed daily, after gentle cleaning, with a moist nonabsorbent dressing (3). If lesions become chronic they may eventually need skin grafting to cover the defect. With regard to leaving the patient under field conditions, it is often prudent to evacuate the casualty for a period of recuperation, as recovery is usually rapid if the correct treatment is instigated.

\section{Question 2}

a. The treatment suggestions given by the members of the group are common lay misconceptions about the management of snakebites and should be avoided. Reassure the patient, wash the wound and apply a clean dressing over it, make the casualty a stretcher case and radio for casualty evacuation.

b. Pit viper or coral snake

c. Arrange for immediate casualty evacuation to a definitive medical care facility with the ability to give anti-venom.

\section{Discussion}

Important measures to prevent snakebites occurring in the first place include boots, long trousers, avoiding placing body parts in likely snake habitats (under rocks, in caves, swampy areas), generally being alert to the risks when in a potential snake habitat and heightened awareness during rainy periods $(4,5)$.

Medically important poisonous snakes fall broadly into two groups, elapids and viperidae (4). Viperidae have long hinged teeth and an arrow-like neck and head. They rapidly inject high doses of venom, which may cause severe local effects (pain, swelling, blistering, bruising, tissue necrosis) along with devastating haemorrhagic effects (mucosal bleeding, stroke, retroperitoneal or gastro-intestinal bleeding, hypovolaemia and DIC). Elapids (cobras, kraits and coral snakes) have fixed teeth, a straight body, neck and head. They inject venom by chewing. They cause neurotoxicity with symptoms including flaccid paralysis and death due to respiratory failure. All snake venom may cause rhabdomyolyis, anaphylaxis, nausea, vomiting and arrythmias.

Being bitten by a snake is a very frightening experience and the resulting sympathetic response will accelerate the systemic absorption of venom (6).

The two most important aspects of management are reassurance by attempting to calm the casualty down, which decreases cardiac output and retards venom distribution, and immediate casualty evacuation to a definitive care facility with the ability to give anti-venom $(4,7-9)$.

First aid management involves supportive therapy and retarding envenomation by

- Assessing ABC including IV access and fluids if required.

- Washing away excess venom from the wound with clean water.

- Applying a sterile dressing.

- Immobilising the limb with a splint and keeping the casualty still - making him a stretcher case will accomplish this in practical terms. 
- Making the limb dependent.

\section{Question 3}

a. Differential diagnosis includes malaria, tick-borne fevers, yellow fever, typhoid, HIV seroconversion, viral haemorrhagic fevers and non-tropical causes of fever such as a chest infection or meningitis. Noninfective causes such as inflammatory or neoplastic conditions should also be considered.

b. Evacuate to definitive care facility for investigation and subsequent treatment.

\section{Discussion}

This patient has a pyrexia of unknown origin (PUO). Fever is a common symptom in the tropics, and has a wide differential diagnosis depending on the location and pattern of diseases endemic to the area. A full history and examination is required, with particular emphasis on any localising symptoms such as headache, cough or diarrhoea, and any physical signs such as a rash, lymphadenopathy, splinter haemorrhages or hepatosplenomegaly. Ideally the temperature should be measured at least twice daily to look for patterns in the fever. Local patterns of disease should be considered, and local expertise sought. In some areas, it is routine to give all patients with fever malaria treatment as a therapeutic trial.

Investigations (in the absence of localising symptoms and signs) should include thick and thin films for malaria and other parasites, WCC including differential, and blood cultures. Non-tropical causes and non-infective causes of PUO should also be considered. For a good summary of the topic see the recent review by Suh et al (10).

\section{Question 4}

a. Push the tick further in, twist 360 degrees, and pull out.

b. Lyme disease, haemorrhagic fevers, relapsing fevers and typhus fevers.

c. Any new symptoms may be significant, in particular a rash, fever, myalgia, headache or lymphadenopathy.

\section{Discussion}

Ticks should be removed as soon as possible after being found. In most cases this will prevent disease transmission, which can take many hours. The multitude of different ways used to remove ticks gives an indication of how difficult it can be. An understanding of entomology provides one of the best answers for their removal. The jaw parts are like ratchets with spikes sticking out into the skin, which can be disengaged facilitating removal. This is accomplished by pushing the tick jaw parts deeper into the skin, turning the tick either clockwise or anticlockwise by 360 degrees and simply pulling it out as the spikes will now be wrapped around the jaw parts. Above are some examples of tick-borne diseases - the most likely disease will depend on which country you are in and whether in a rural or urban environment (11). Antibiotics may play a role as prophylaxis after a tick bite in areas where certain tick-borne diseases are known to be endemic (12).

\section{Question 5}

a. The correct term is cutaneous myiasis, which is caused by the maggots of Dermatobia hominis. It is well known to servicemen as the botfly.

b. Conservative or surgical treatment (see below).

c. Universal barrier precautions along with ironing clothes (including any underclothes worn) are important preventative steps.

\section{Discussion}

Cutaneous myiasis is endemic in Central and South America (13). The adult botfly catches a biting insect (e.g. a mosquito, fly or tick) and attaches eggs to the underside of its victim. When this second insect bites the human the eggs are deposited on the skin where they hatch into larvae that burrow under the skin. Left undisturbed for 5-10 weeks a mature larva will emerge that drops to the ground and pupates into an adult fly (14). Larvae and eggs can also be deposited on washing that is hanging out to dry, necessitating the precautions outlined above. Diagnosis is usually obvious because of the central breathing hole in the furuncular lesion, although earlier in the life cycle it is easy to misdiagnose as a simple boil. Some patients can feel a crawling sensation under their skin (13).

Treatment is often more problematic, with conservative or surgical options. Smothering it with petroleum jelly or waterproof tape to obstruct the larva's air supply and removing it after 24 hours, or injecting local anaesthetic under the lesion are the methods of choice, but in practice this is not always successful (13). Excision using a cruciate incision may be more effective (15). Use of lignocaine with adrenaline (if not contra-indicated) may be of use as the surrounding area will be very vascular. Due to the size of the larvae (up to $2.5 \mathrm{~cm}$ by $0.5 \mathrm{~cm}$ ) and the fact that they often burrow deep into tissues a surgical referral is often necessary. 


\section{Question 6}

a. Delayed presentation, characteristic appearance and known presence in an endemic area.

b. He should be referred for specialist investigation and treatment.

c. The sandfly.

d. Use of universal precautions (long sleeves, long trousers, insect repellent, nets) cannot be overstated for prevention of all tropical infections. Impregnation of nets with insecticide (such as Peripel), although not preventing sandfly access, will kill them on their way through the netting.

\section{Discussion}

The major clinical syndromes of leishmaniasis are visceral, cutaneous, and mucosal, and are the result of protozoal infection of macrophages in the reticuloendothelial system, skin and oronasal mucosa respectively. It is spread by the female sandfly of the genus Lutzomyia (16). The endemic area for cutaneous leishmaniasis in the Americas extends from Texas in the north to Argentina in the south. After being bitten, the cutaneous lesion develops over weeks and months, starting as a nodule or papule, which eventually breaks down to form an ulcer with raised erythematous borders. Diagnosis is often delayed - in a study of 58 patients, Herwaldt et al found a median time to diagnosis and treatment of 112 days from when patients first noticed the lesions (17). Long term effects of cutaneous leishmaniasis include scarring, bacterial superinfection, and progression to mucosal leishmaniasis. Diagnosis is often difficult, but should be suspected in any lesion that does not respond to a course of antibiotics (see question 1 above), in a patient who has visited an endemic area. It can be confirmed by Giemsa-stained thin smears of dermal scrapings of ulcerative lesions (18).

Sodium stibogluconate still forms the basis of treatment. Prevention is, as is so often the case, easier than cure. Universal precautions are vital, but as sandflies are about one third of the size of a mosquito, they may get through a standard net. Use of finer mesh nets or impregnation of nets with insecticide reduces the risk of infection.

\section{References}

1. Manson-Bahr PEC, Bell DR. Manson's tropical diseases, nineteenth edition, Balliere Tindall, 1987.

2. Bell DR. Lecture notes on tropical medicine, fourth edition, Blackwell Scientific Publications, 1991.

3. Eddleston M, Pierini S. Oxford handbook of tropical medicine, Oxford University Press, 1999.

4. Warrell DA. Venomous bites and stings in the tropical world. Med f A ust 1993; 159: 773-779.

5. Blackman JR, Dillon S. Venomous snakebite: past, present, and future treatment options. F Am Board Fam Pract 1992; 5(4): 399-405.

6. Murdock RT, White GL Jr, Pederson DM, DeFaller JM, Snyder CC. Prevention and field management of venomous snakebites during military exercises. Mil Med 1990; 155(12): 587590.

7. McKinney PE. Out-of-hospital and interhospital management of crotaline snakebite. Ann Emerg Med 2001; 37(2): 168-74.

8. Haviv J, Huerta M, Shpilberg O, Mimouni D, Ash N, Grotto I. Field treatment of snakebites in the Israel Defense Forces. Public Health Reviews 1998; 26(3): 247-56

9. Smith TA, Figge HL. Treatment of snakebite poisoning. Am f Hosp Pharm 1991; 48(10): 2190-6.

10. Suh KN, Kozarsky PE, Keystone JS. Evaluation of fever in the returned traveler. Med Clin N Amer 1999; 83(4): 997-1017.

11. Parola P, Raoult D. Ticks and tick-borne bacterial diseases in humans: an emerging infectious threat. Clin Infect Dis 2001; 32(6): 897-928.

12. Maiwald $\mathrm{M}$, Oehme $\mathrm{R}$, March $\mathrm{O}$ et al. Transmission risk of Borrelia burgdorferi sensu lato from Ixodes ricinus ticks to humans in southwest Germany. Epidemiol Infect 1998; 121(1): 103-8.

13. Johnston M, Dickinson G. An unexpected surprise in a common boil. $f$ Emerg Med 1996; 14(6): 77981.

14. Dondero TJ Jr, Schaffner W, Athanasiou R, Maguire W. Cutaneous myiasis in visitors to Central America. South Med F 1979; 72(12): 150811.

15. Richards KA, Brieva J. Myiasis in a pregnant woman and an effective, sterile method of surgical extraction. Dermatol Surg 2000; 26(10): 955-957.

16. World Health Organization. Control of the Leishmaniases. Geneva, WHO Technical Report Series 793,1990 .

17. Herwaldt BL, Stokes SL, Juranek DD. American cutaneous leishmaniasis in US travellers. Ann Intern Med 1993; 118(10): 779-84.

18. Navin TR, Arana FE, de Merida AM, Arana BA, Castillo AL, Silvers DN. Cutaneous leishmaniasis in Guatemala: comparison of diagnostic methods. Am F Trop Med Hyg 1990; 42: 36-42. 